\section{ARTICLE}

Tullio Buccellato, Dominic Webber, Sean White, Felix Ritchie and Shadia Begum Office for National Statistics

\title{
The economic impact of tourism across regions and
nations of the UK
}

\section{Introduction}

$T$ resin ourism as a sector is often considered, perhaps mistakenly, as a relatively minor engine of economic development when compared with sectors such as retail or manufacturing. It is recognised, however, that tourism can play a major role in relieving poverty in developing regions and countries, and in supporting the regeneration of obsolete and run-down parts of cities in developed countries. The study of tourism's economic impact becomes perhaps more relevant in the regional context, due to its natural dependence on specific locations and amenities. In the case of the United Kingdom, a recognised lack of coordination in the production of official statistics for tourism both at the national and regional level renders even more difficult a precise evaluation of the net economic effects of the sector on both the national and the regional economies. This paper represents a groundbreaking study in presenting a simple accounting methodology for the production of regional figures consistent with national headline figures contained in the Experimental UK Tourism Satellite Account (E-UKTSA) ${ }^{3}$ currently under production in the ONS. The final aim of our methodology is to reconcile the demand and supply of tourism related activities at the regional level in the UK.

Measuring the volume of tourism requires the simultaneous consideration of its demand and supply components. Tourism as an activity is defined by what tourists do and what they spend their money on - it is defined by tourism demand, not by any formal classification by industry or sector.
Expenditure by tourists takes place in many different industrial sectors, and constitutes a varying proportion of the total expenditure in each of those sectors. In addition, the measurement of tourism is made even more complex by the lack of a production function and a clearly identifiable output. Finally, tourism is characterized by highly fragmented demand, which is served to a significant degree by small and mediumsized firms. This poses further problems of measurement due to the difficulties of measuring the economic activities of very small firms, which are more difficult to survey.

The measurement of tourism's economic impact represents a complex procedure even at the national level. National headline figures resulting from synthesizing different sources of information are, however, sufficiently accurate and allow for the reconciliation of demand and supply side activities. The production of national data on tourism economic activity is per se very important in that it represents an important step forward in comparing the performance of the sector both internationally and across industrial sectors. The methodological framework to obtain national figures is standardized and promoted internationally through the Tourism Satellite Account (TSA). The TSA allows for the computation of a demand to supply ratio, which is considered central in the TSA framework allowing for the computation of TD-GVA.

The measurement of tourism subnationally is more demanding. The same data sources used to obtain national figures 
become less accurate when considered at a lower degree of aggregation (for example regionally rather than nationally or, in a time perspective, quarterly rather than annual) and more volatile over time. There is also a lack of well established international recommendations. The TSA is broadly recognized as the most appropriate method to measure the economic impact of tourism but, being based on Supply and Use Tables (SUT) produced at the national level, is not easily adaptable to sub-national estimates. Notwithstanding these difficulties, the TSA framework can be adopted to play a fundamental role in the production of regional figures. The construction of the TSA represents a complex exercise of classification of all the data sources available to measure the components of tourism demand and supply and represents a necessary step in building up the expertise to move to the subnational level measurements.

In the remainder of this paper a simple methodology to reconcile the demand and supply of tourism is proposed and accompanied by some preliminary figures. The methodology is mainly designed to allow English Regional Development Agencies to assess the contribution of tourism within regions in a consistent form, allowing a robust performance comparison across regions. The current work is part of the wider context of the development of an Integrated System of Tourism Statistics (ISTS) within the Tourism Intelligence Unit (TIU) at ONS, whose central component is the E-UKTSA. Regional figures are produced to be consistent with the headline figures reported in the E-UKTSA. The following section introduces ONS methodology for reconciling demand and supply figures of tourism related economic activities and details the steps leading to the computation of our TD-GVA figures. The third section displays figures based on the methodology. Section four draws some conclusions and pointers for further research.

\section{A simple methodology to reconcile demand and supply of tourism}

The methodology presented in the current work is mainly aimed at optimizing the amount of information from all the data sources available at the regional level. This is achieved through compiling and analysing data which are produced within ONS and also data sourced externally. ONS data sources entirely cover the measurement of the supply side of tourism, in other words the ensemble of industries grouped by international recommendations in the Standard International Code of Tourism Activities (SICTA), which includes 42 fivedigits SICs aggregated in 10 industries (Box 1 summarizes the SIC codes by industry). On the demand side, the only component of tourists' consumption measured within the ONS is the inbound expenditure of tourists. The consumption of overnight domestic tourism and the expenditure of domestic excursionists (or tourism day visits) are all collected from external suppliers.

The Annual Business Inquiry (ABI) 2006, which includes a scaling factor to ensure that data are representative at the regional level, is the main source for measuring the supply side of tourism. The first step in constructing a measure of Gross Value Added of Tourism Industries (GVA-TI) is to generate a GVATI(\%) measure in order to apportion the total supply of commodities to those in the tourism related SICTAs.

The GVA-TI(\%) statistic reports GVA in the SICTAs (see Box 1) as a percentage of total GVA, such that

$$
G V A-T I(\%)=\frac{\sum_{n=1}^{N} G V A_{i}^{A B I}}{\sum_{k=1}^{K} G V A_{i}^{A B I}} \times 100
$$

where $n=1,2, \ldots, 42$ is meant to sum GVA over SICTAs and $k=1,2, \ldots, 638$ sum the GVA over the complete set of 5-digits SICs composing the whole economy. This ratio is important for showing the relative importance of tourism related activities in relation to the overall regional economy.

Although GVA-TI(\%) is derived from a unique dataset and hence has the advantage of internal consistency, there are two important issues to bear in mind when interpreting the statistics. First, tourism is defined by the activities of tourists and what they spend their money on - so is a demand rather than a supply concept. Tourists' spending only accounts for a proportion of the expenditure recorded in each sector of the tourism-related industries, the balance representing the expenditure of residents in those sectors. Therefore, in producing

\section{Box 1}

\section{International definition of tourism related sectors defined on the basis of SIC07 codes}

\begin{tabular}{|c|c|c|c|}
\hline Industry & SIC07 & Industry & SIC07 \\
\hline Railway passenger transport. & 49100 & Transport Equipment Rental & 77110 \\
\hline \multirow{2}{*}{ Road Passenger transport } & 49320 & & 77341 \\
\hline & 49390 & & 77351 \\
\hline \multirow[t]{2}{*}{ Water Passenger transport } & 50100 & Sporting and recreational activities & 77210 \\
\hline & 50300 & & 92000 \\
\hline \multirow[t]{2}{*}{ Air Passenger transport } & 51101 & & 93110 \\
\hline & 51102 & & 93199 \\
\hline \multirow[t]{6}{*}{ Accommodation for Visitors } & 55100 & & 93210 \\
\hline & 55201 & & 93290 \\
\hline & 55202 & Country-specific tourism characteristic activities & 82301 \\
\hline & 55209 & & 82302 \\
\hline & 55300 & Cultural Activities & 90010 \\
\hline & 55900 & & 90020 \\
\hline \multirow[t]{9}{*}{ Food and beverage serving activities } & 56101 & & 90030 \\
\hline & 56102 & & 90040 \\
\hline & 56103 & & 91020 \\
\hline & 56210 & & 91030 \\
\hline & 56290 & & 91040 \\
\hline & 56301 & & \\
\hline & 56302 & & \\
\hline & 68209 & & \\
\hline & 68320 & & \\
\hline
\end{tabular}


TD-GVA some further apportionment is required.

Second, this index can suffer from an under-representation of small firms which are below the $£ 61,000$ VAT threshold since one of the main sources of data excludes firms not VAT registered. For firms below the $£ 61,000^{4}$ VAT threshold it is not compulsory to report their turnover to Revenues and Customs (HMRC), which represents the main source to update the Inter Departmental Business Register (IDBR) 5 . The ABI itself represents a stratified sample drawn from the IDBR.

ABI data version used in this study includes 110,292 observations in total, of which 9.3 per cent are below the VAT threshold. The percentage of firms below the VAT threshold decreases to 7.3 per cent when only considering the firms operating in tourism related industries, which total 21,691 . These results are reversed, however, when considering the economic importance of small firms. The share of turnover produced by small firms represents 8.6 per cent when considering the overall economy but increases to 17.3 per cent when looking only at the SICTAs. This apparently counterintuitive effect is mainly due to the weights used to rescale the turnover variable. The weighting system seems to reflect the broadly accepted view that tourism as a sector is reliant to a large degree on medium and small enterprises.

The formula for GVA-TI(\%) can also be computed at the regional level providing a good indicator to compare regional economic performance.

This ratio can be used to calculate $S P-T I_{i}^{S U T}$ which denotes the tourism related supply of products at purchaser prices for each of the $i=1,2, \ldots, 12$ regions and expressed in SUT units.

$$
\begin{aligned}
S P-T I_{i}^{S U T} & =\left(\frac{T O T G V A_{i}^{A B I}}{T O T G V A_{U K}^{A B I}} \times T O T-S P^{S U T}\right) \\
& \times G V A-T I(\text { Ratio })_{i}^{A B I}
\end{aligned}
$$

The first part of the formula (in brackets) computes the total supply of products at purchaser prices in each region by using GVA shares based on the ABI to apportion the total supply reported in the SUT (TOT-SPSUT). Using the SUT as a numeraire allows regional totals summing up to national UK figures to be obtained.

The second part of the formula uses the GVA-TI(Ratio) to compute what is attributable to the tourism related industries present in region $i$. This gives regional totals of tourism related supply of products at purchasers' prices.

Having constructed a comprehensive set of figures for the supply side the next task is to identify the expenditure on domestic tourism, and to use this to proportion the supply-side measure of GVA in tourism-related industries as between tourists and residents 'at leisure'. The essential point is that tourism is defined as the activities and expenditure of 'visitors' or 'tourists' - these are people away from their 'usual environment' of where they live, work and go about their daily life. 'Leisure' is a term used in this context to describe the similar activities and expenditure of people but within their usual environment, such as residents. Taken together, they account for the expenditure in the tourism related industries.

Calculating UK tourism consumption is more complex due to the numerous data sources that exist. Furthermore these data sources change according to the component of the tourism consumption being considered. There are four components of tourism consumption which need to be captured:

- spending within the UK by inbound visitors from overseas

- spending by domestic overnight visitors

- spending on day visits (sometimes called 'excursionists'); and

- domestic spending of outbound residents on aspects of an overseas trip before they leave the UK

As mentioned already the only demand component measured in ONS is the expenditure of inbound visitors through the International Passenger Survey (IPS). The expenditure of domestic overnight visitors is contained in the UK Tourism Survey (UKTS) implemented by Taylor Nelson Sofres (TNS) and commissioned by the national tourist boards. Tourism day visits expenditure is measured by the English Leisure Visits Survey (ELVS) from 2005 which was commissioned by English Nature and the National Parks in England. VisitBritain have conducted a projection exercise which gives data covering day visit expenditure for England, Scotland, and Wales. Here, however data from a previous survey, the Great Britain Day Visit Survey (GBDVS) is also relied on from 2002/3 to apportion expenditure shares across the Great Britain regions as this information is not available from ELVS Therefore, in the remainder of the paper the acronym GBDVS/ELVS reflects the use of the two surveys to arrive at day visit expenditure data at the regional level. The last component of the demand side is represented by the domestic expenditure of outbound tourists before leaving the country. This is the only component for which data sources are not available and some degree of modelling is required.

The IPS, UKTS and GBDVS/ELVS are all available at the regional level. The expenditure on tourism day visits for Northern Ireland is not covered by the GBDVS/ELVS and obtained from a Tourism Satellite Account based on a reference year of 2003. Data from IPS and UKTS are transformed in three years averages to smooth out possible anomalous features. Based on the three years averages, regional shares are computed and applied to headline figures of the E-UKTSA.

The consumption of outbound tourism flows is modelled on the basis of the sectoral structure as broken down in the E-UKTSA. Regional shares for each of the components are then computed through the $\mathrm{ABI}$ to apportion the tourism industries total as reported in the E-UKTSA. As an example, consider the domestic outbound tourism expenditure in railways. Table 2 of the E-UKTSA reports a figure of around $£ 482$ million for the expenditure of domestic outbound tourists in railway passenger transport before leaving the country. In order to apportion this figure across regions the $\mathrm{ABI}$ is used to compute the turnover shares of each region within the railway passenger sector. Regional total domestic expenditure is obtained as follows:

$$
\begin{aligned}
\text { DomOutExp }_{i}= & \left(\sum_{k=1}^{5} \frac{\text { Turnover }_{i, k}^{A B I}}{\text { Turnover }_{k}^{A B I}}\right) \\
& \times \text { Expenditure }_{k}^{E-U K T S A}
\end{aligned}
$$

where $k=1,2, \ldots, 5$ is used to compute shares and apportion over the five main components of outbound tourists' domestic expenditure - railway passenger transport, road passenger transport, water passenger transport, air passenger transport, travel agencies and other reservation services activities. The simple apportionment formula also makes clear that the shares are based on the ABI and these are then used to apportion the headline figures from the E-UKTSA.

Such an approach allows a robust approximation of the regional figures for outbound tourists' domestic expenditure where direct data sources are not available although two warnings need to be provided. First, using a supply side data source to apportion a demand component brings with it an evident conceptual contradiction. Second, the regional shares for each of the individual tourism industries as defined by international recommendations can equal zero. This in some cases brings some very counter-intuitive results, for example stating 


\section{Figure 1}

\section{A graphical representation of the methodology to compute the regional values of tourism}

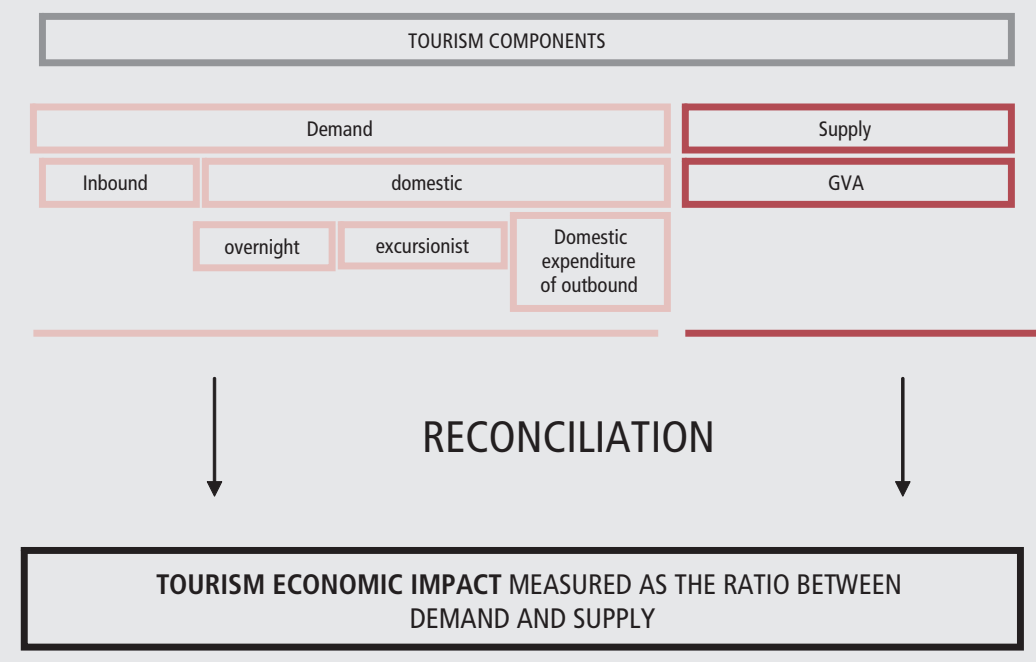

Source: TIU

Table 1

The economic impact of tourism by regions and nations for the year 2006

\begin{tabular}{lrrrrrr}
\hline Region & $\begin{array}{r}\text { Total tourism } \\
\text { expenditure } \\
\text { (billion) }\end{array}$ & $\begin{array}{r}\text { Total GVA } \\
\text { (billion) }\end{array}$ & $\begin{array}{r}\text { GVA-TI } \\
\text { (per cent) }\end{array}$ & $\begin{array}{r}\text { DSR } \\
\text { (per cent) }\end{array}$ & $\begin{array}{r}\text { GVA-TI } \\
\text { (billion) }\end{array}$ & $\begin{array}{r}\text { TDGVA } \\
\text { (billion) }\end{array}$ \\
\hline East Midlands & 5.2 & 74.7 & 5.1 & 2.8 & 3.8 & 2.1 \\
Eastern & 9.8 & 102.1 & 6.3 & 3.8 & 6.4 & 3.9 \\
London & 20.7 & 247.5 & 8.2 & 3.4 & 20.3 & 8.3 \\
North East & 2.8 & 35.9 & 6.0 & 3.1 & 2.1 & 1.1 \\
North West & 7.9 & 108.6 & 8.3 & 2.9 & 9.0 & 3.1 \\
South East & 18.2 & 181.9 & 8.0 & 4.0 & 14.6 & 7.2 \\
South West & 7.6 & 76.9 & 8.9 & 4.0 & 6.9 & 3.1 \\
West Midlands & 6.3 & 89.7 & 6.2 & 2.8 & 5.5 & 2.5 \\
Yorkshire and the Humber & 5.2 & 81.3 & 5.6 & 2.5 & 4.6 & 2.1 \\
Total England & 83.7 & 998.6 & 7.3 & 3.3 & 73.3 & 33.4 \\
& & & & & & 0.7 \\
Northern Ireland & 1.9 & 29.8 & 6.7 & 2.5 & 2.0 & 0.3 \\
Scotland & 8.5 & 113.4 & 5.2 & 3.0 & 5.9 & 3.4 \\
Wales & 4.0 & 35.5 & 7.9 & 4.5 & 2.8 & 1.6 \\
Total UK & & & & & & 39.2 \\
\hline
\end{tabular}

Source: Annual Business Inquiry 2006, Supply and Use Tables 2006, International Passenger Survey (average 2006, 2007, 2008), UK Tourism Survey (average 2006, 2007, 2008), Great Britain Day Visit Survey 2002/3, English Leisure Visits Survey, 2005, Authors' calculations

that the share of passenger railway transport in a given region could be zero.

Reconciliation between demand and supply sources is then obtained by computing the 'demand to supply' ratio. This represents the most important figure within the TSA framework ${ }^{6}$, reflecting a simple ratio of the sum of all the demand side data components to the total obtained from the supply side data components:

\section{TotInbExp $_{i}+$ TotDomNightExp $_{i}$ $D S(\text { ratio })_{i}=\frac{+ \text { TotDomDayVis }_{i}+\text { TotOutDomExp }}{i}$}

This simple ratio is usually expressed as a percentage. In the numerator all the components of tourism for each of the 12 regions $i=1,2, \ldots, 12$ are summed - these are total inbound tourism TotInbExp, total domestic overnight expenditure TotDomNightExp ${ }_{i}$, total domestic expenditure by day visitors TotDomDayVis, and total domestic expenditure of outbound tourists before they leave the region TotOutDomExp $p_{i}$ . The denominator is just the total supply of products at purchasers' prices for the region $i$ in SUT units apportioned through the ABI.

Figure 1 provides a graphical summary of the most important demand and supply components to be reconciled.

Finally, the demand to supply ratio can be employed to obtain figures for Tourism Direct Gross Value Added (TDGVA). The total Gross Value added of the UK is reported in the SUT which is apportioned by region using ABI based shares and then multiplied by the DS(Ratio):

$T D G V A_{i}^{S U T}=G V A_{i}^{S U T} \times D S(\text { Ratio })_{i}$

It is worth stressing that although all the most important figures present in the TSA can be reported it is not possible, however, to attain the complete TSA framework at the regional level. This is mainly due to the lack of regional SUTs, which would enable the regional breakdown of TDGVA sector by sector.

\section{Results based on the methodology}

Table 1 summarises the main indicators obtained by implementing the methodology outlined in this article. The rest of this section then presents further data on the supply side of tourism and its demand components, and finally showing how the two are reconciled in the construction of the TD-GVA statistic.

Figure 2/Table 2 compares the shares of each UK region in the total and tourismspecific economies. The respective figures are taken from the numerator and the denominator of the GVA-TI(\%) formula. London accounts for around 21 per cent of the overall UK GVA and around 24 per cent in the tourism economy. Relative shares of the tourist economy compared to the share of the overall economy are also higher in Wales, the South West, the South East and the North West.

It is also worth considering that there may be a downward bias in the respective shares of the tourism sector for regional economies with a relatively higher share of rural activities. For example, if a farm rents out tourist accommodation during seasonal peaks of the year, but the turnover generated by this activity does not exceed the turnover generated by the farm in agriculture connected activities, then the enterprise would be classified as operating in the agriculture sector in the ABI and not included in the measurement of tourism related activities.

Figure 3/Table 3 displays the GVA generated by tourism industries (GVA-TI) expressed in percentages of total GVA for each region. The South West is the region displaying the highest share of tourism activities to the overall economy (8.91 per cent), followed by North West (8.31 per cent), London (8.22 per cent), South East (8.04 per cent) and Wales (7.92 per cent). The figures presented in Figure 3 are still exclusively 


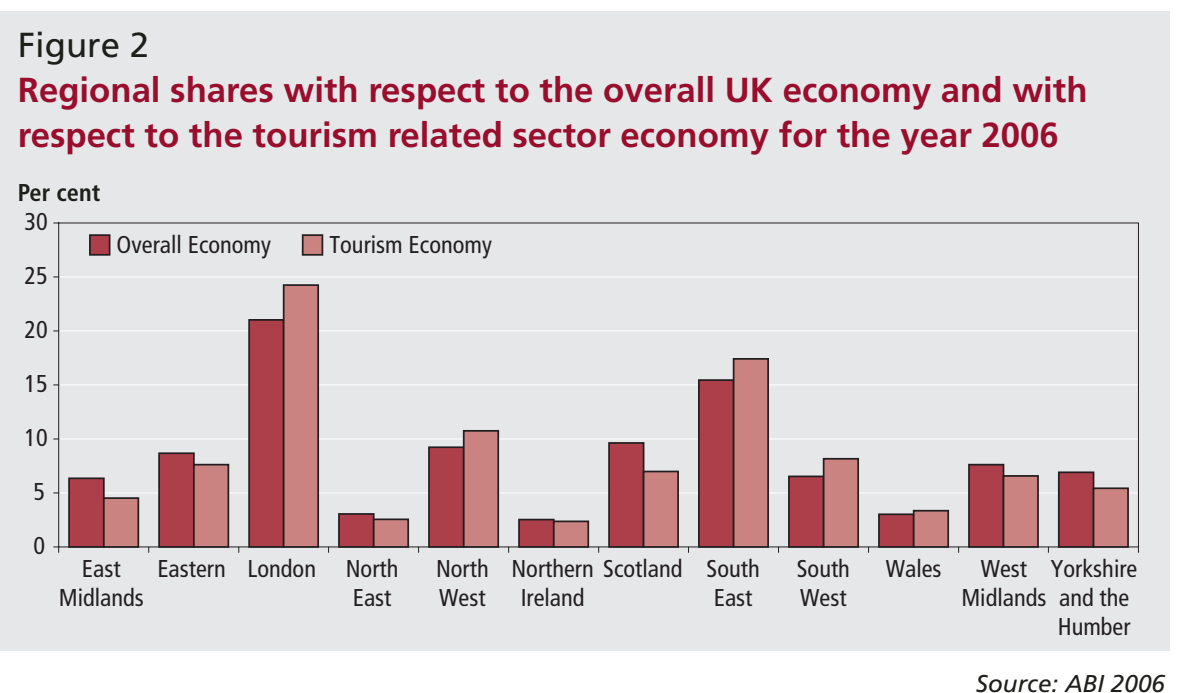

Table 2

\section{Regional shares with respect to the overall UK economy and with respect to the tourism related sector economy for the year 2006}

\begin{tabular}{|c|c|c|}
\hline Region & Overall economy (per cent) & Tourism economy (per cent) \\
\hline East Midlands & 6.3 & 4.5 \\
\hline Eastern & 8.7 & 7.6 \\
\hline London & 21.0 & 24.3 \\
\hline North East & 3.0 & 2.6 \\
\hline North West & 9.2 & 10.8 \\
\hline South East & 15.5 & 17.4 \\
\hline South West & 6.5 & 8.2 \\
\hline West Midlands & 7.6 & 6.6 \\
\hline Yorkshire and the Humber & 6.9 & 5.4 \\
\hline Total England & 84.8 & 87.3 \\
\hline Northern Ireland & 2.5 & 2.4 \\
\hline Scotland & 9.6 & 7.0 \\
\hline Wales & 3.0 & 3.4 \\
\hline Total UK & 100.0 & 100.0 \\
\hline
\end{tabular}

Source: $A B I 2006$

Figure 3

\section{GVA-TI in regional/national economies, 2006}

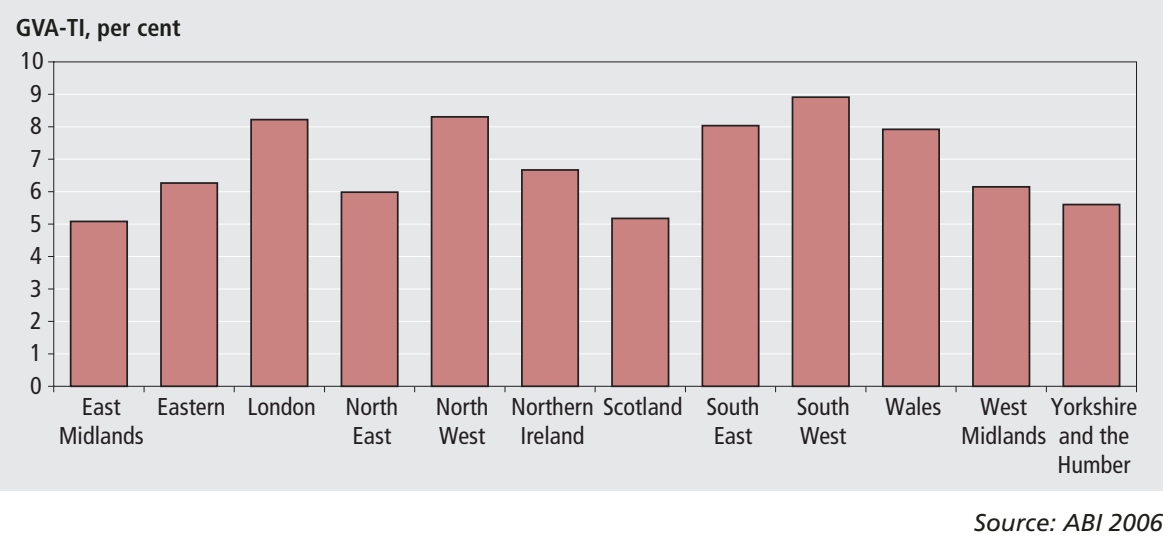

based on the production side of the tourism sector and, hence, they cannot be considered as consumption trends of the sector.

Turning to the demand side, Figure 4/

Table 4 reports for each region the values of tourism expenditure broken down into the four component parts. London displays the highest level of expenditure derived from inbound visitors, in the order of $£ 8$ billion. This reflects the importance of London as a pole of attraction for leisure tourists as well each. These figures are possibly explained by the population distribution as amenities close to more populated areas have a clear comparative advantage in attracting excursionists. It is also worth stating at this stage that the figures presented for day visitors do not include business day visitors and are representative only of excursions, or day visits, undertaken during the persons own time.

The final component of tourism consumption is represented by the domestic expenditure of outbound tourists DomOutExp. As discussed in the previous section this is the only component for which direct data sources are not available and for which some degree of modelling is required. Domestic consumption of outbound tourists seems to be very unevenly distributed across regions with London and the South East together accounting for sixty percent of the overall total figure. This could be supported by the fact that London represents the main route to overseas countries by air (with four international airports) and the South East is the region with the highest proportion of water passenger transport.

We have separated this last component within the table from the inbound and domestic expenditure as the latter refers more specifically to tourism expenditure in terms of the UK as a destination, for many in the sector this expenditure will be of particular interest for policy purposes.

The Demand to Supply Ratio represents a good measure of the economic importance of the tourism sector within regions. Figure 5 displays the ranking of the regions. Wales turns up to be top ranked with around 4.5 per cent followed by South East and South West both with 4 per cent.

The demand to supply ratio is the central part of the analysis because it allows for the computation of the Tourism Direct GVA (TDGVA). TDGVA represents the amount of GVA directly coming from visitors' expenditure and represents the most 'accurate' figure for tourism expenditure. The demand to supply ratio is important for showing what share of the sector is directly connected to tourists and what share is instead generated by residents' expenditure. The value of regional TDGVA is presented in Figure 6.

The results suggest London and the South East contribute most significantly to tourism within the UK with a joint supply share over 35 per cent and a demand share around 40 per cent. However, London has a disproportionate share of inbound tourism (about half of all inbound tourism spending in the UK takes place in London) and a relatively low share of domestic tourism. 
Table 3

The domestic supply at purchasers' prices for the overall regional/ national economies and for the tourism industries, 2006

\begin{tabular}{lrrr}
\hline Region & Total GVA (billion) & GVA-TI (billion) & GVA-TI (per cent) \\
\hline East Midlands & 187 & 10 & 5.1 \\
Eastern & 256 & 16 & 6.3 \\
London & 620 & 51 & 8.2 \\
North East & 90 & 5 & 6.0 \\
North West & 272 & 23 & 8.3 \\
South East & 456 & 37 & 8.0 \\
South West & 193 & 17 & 8.9 \\
West Midlands & 225 & 14 & 6.1 \\
Yorkshire and the Humber & 204 & 11 & 5.6 \\
Total England & 2502 & 183 & 7.3 \\
Northern Ireland & 75 & 5 & 6.7 \\
Scotland & 284 & 15 & 5.2 \\
Wales & 89 & 7 & 7.9 \\
Total UK & 2949 & 210 & 7.1 \\
\hline
\end{tabular}

Source: $A B I 2006$

\section{Figure 4}

The demand components of tourism across regions for the year 2006

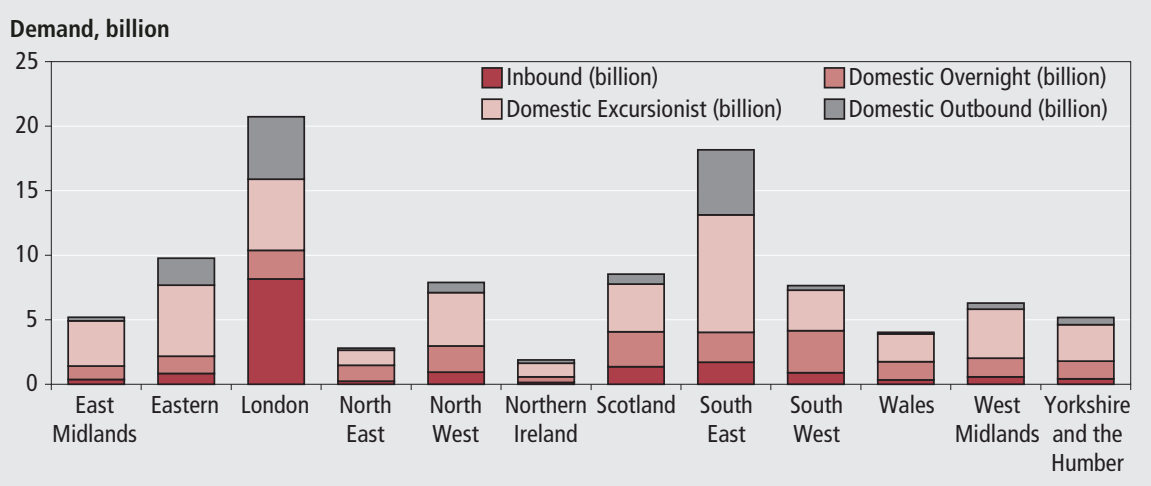

Source: As Table 4

Table 4

The demand components of tourism across regions for the year 2006

\begin{tabular}{|c|c|c|c|c|c|}
\hline \multirow[b]{2}{*}{ Region } & \multicolumn{3}{|c|}{ UK as a destination } & \multirow{2}{*}{$\begin{array}{r}\text { Expenditure } \\
\text { in UK of } \\
\text { tourists } \\
\text { going } \\
\text { outbound } \\
\text { (billion) }\end{array}$} & \multirow[b]{2}{*}{$\begin{array}{r}\text { Total Demand } \\
\text { (billion) }\end{array}$} \\
\hline & $\begin{array}{r}\text { Inbound } \\
\text { (billion) }\end{array}$ & $\begin{array}{r}\text { Overnight } \\
\text { (billion) }\end{array}$ & $\begin{array}{r}\text { Excursionist } \\
\text { (billion) }\end{array}$ & & \\
\hline East Midlands & 0.4 & 1.0 & 3.5 & 0.3 & 5.2 \\
\hline Eastern & 0.8 & 1.3 & 5.5 & 2.1 & 9.8 \\
\hline London & 8.2 & 2.2 & 5.5 & 4.8 & 20.7 \\
\hline North East & 0.2 & 1.2 & 1.2 & 0.2 & 2.8 \\
\hline North West & 0.9 & 2.0 & 4.1 & 0.8 & 7.9 \\
\hline South East & 1.7 & 2.3 & 9.1 & 5.0 & 18.2 \\
\hline South West & 0.9 & 3.3 & 3.1 & 0.4 & 7.6 \\
\hline West Midlands & 0.6 & 1.5 & 3.8 & 0.5 & 6.3 \\
\hline Yorkshire and the Humber & 0.4 & 1.4 & 2.8 & 0.6 & 5.2 \\
\hline Total England & 14.1 & 16.3 & 38.7 & 14.6 & 83.7 \\
\hline Northern Ireland & 0.1 & 0.4 & 1.1 & 0.3 & 1.9 \\
\hline Scotland & 1.4 & 2.7 & 3.7 & 0.8 & 8.5 \\
\hline Wales & 0.3 & 1.4 & 2.1 & 0.1 & 4.0 \\
\hline Total & 16.0 & 20.8 & 45.6 & 15.7 & 98.1 \\
\hline
\end{tabular}

Source: International Passenger Survey (IPS) for the inbound tourists' expenditure, UK Tourism Survey (UKTS) for the overnight domestic tourists' expenditure, and the Day Visit Surveys (GBDVS/ELVS) for the expenditure of leisure domestic day visitors and authors' calculation for the domestic expenditure of outbound visitors.

However, tourism is clearly important in other regions and nations, in Wales and the South West, for example, there will clearly be much investment in the tourism 'product' and as a result the TDGVA and tourism consumption figures are high in relation to their general economic performance and population.
Conclusions and redirection for further research

Expenditure by tourists in the UK directly accounts for 3.3 per cent ${ }^{7}$ of the overall economy directly connected to tourism related activities. Overall tourism consumption amounts to $£ 98$ billion within the UK economy. This article focuses on regional breakdowns contributing to these national totals highlighting the importance of tourism sector within regions and across regions. Even if the construction of regional TSAs is out of the scope of the present paper, the figures derived from the methodology are presented in a demand-supply framework that is consistent with the headline figures of the E-UKTSA.

When comparing tourism sector performance across regions, there is no doubt that London represents an outlier for both the production and the demand in tourism related activities. This however should be seen in view of another important consideration which is that the performance of regions in terms of tourisms' economic impact tends to be in line with the performance of their overall economy. In that respect London can be considered an outlier also in relation to its share on the overall economy. Some exceptions are represented by Wales and the South West for which the ranking is slightly improved when looking at tourism.

The ranking changes substantially when looking at the reconciliation of demand and supply. The within-regional dimension of the tourism sector would not be affected by the dimension effect of the overall economy, and, hence, this represents a very useful like for like comparison of the importance of tourism related activities across regions. Regions usually lying at the bottom of the ranking based on their contribution to the UK economy can escalate the ladder to the top as is the case with Wales. The demand to supply ratio is very important in that can be directly compared with the national 3.3 per cent figure derived from the E-UKTSA given that its regional counterpart is computed in a completely consistent way.

At this point it is worth commenting further on the difference between the measures of TDGVA ( $£ 39.2$ billion or $3.3 \%$ ) and tourism consumption ( $£ 98.1$ billion). The former is an output or product measure whilst the second is an expenditure or demand measure. The conceptual difference between the two can perhaps be better understood by referring to the Supply Use Tables (SUT) terminology. The demand figure will be higher because it is reported in purchasers' prices as opposed to TDGVA which is reported in basic prices. 


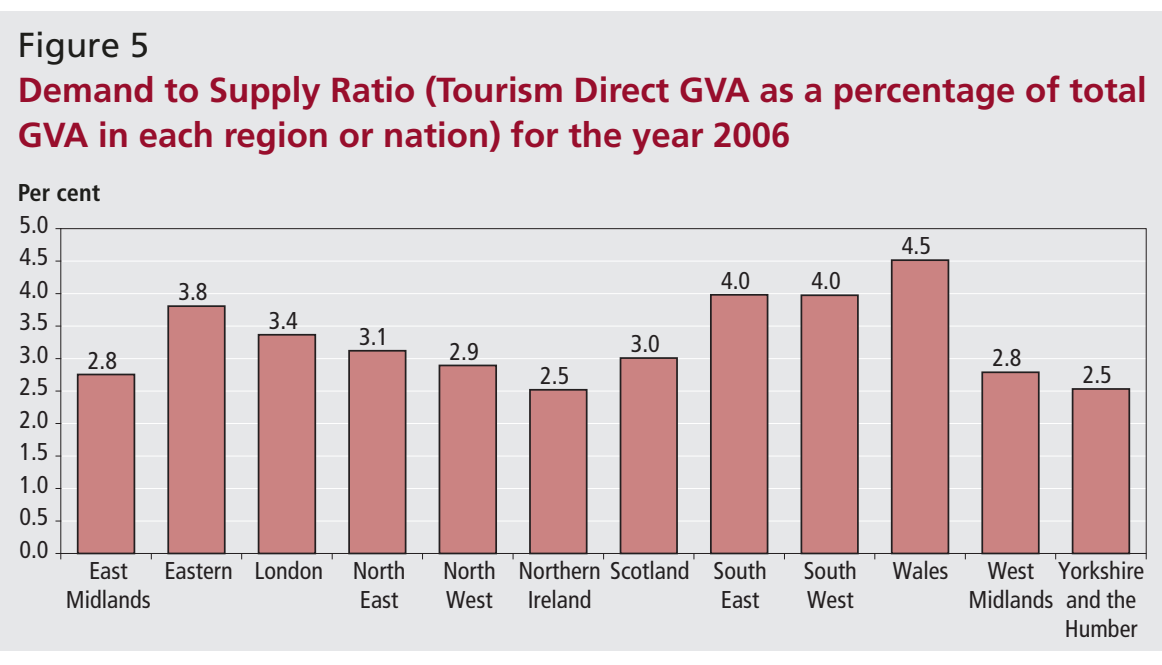

\section{Figure 6}

\section{Tourism Direct GVA expressed in billion pounds for the year 2006}

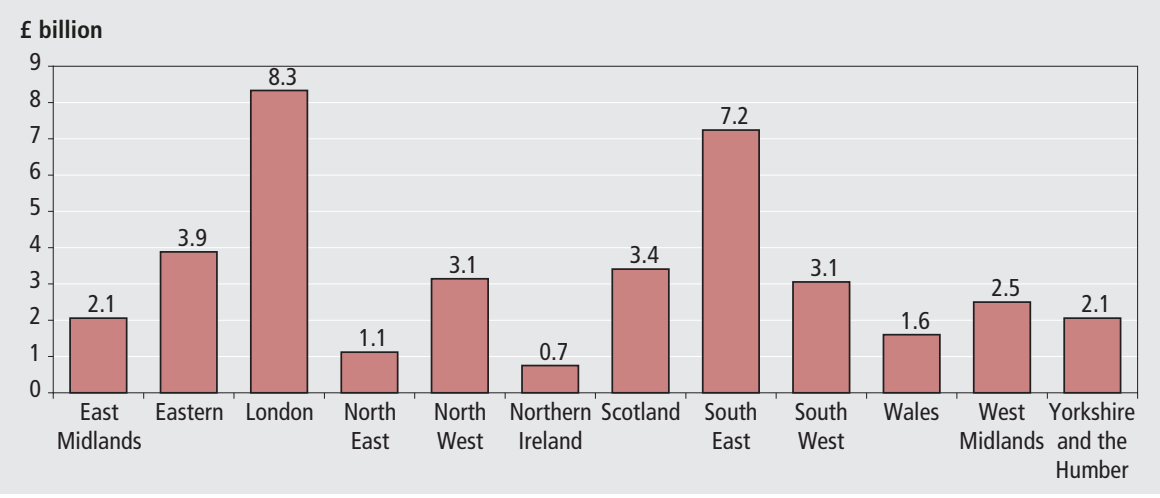

TDGVA incorporates taxes less subsidies on production, compensation of employees, and gross operating surplus and mixed income. The demand figure will also include total intermediate and final consumption at purchasers' prices.

The results presented in this paper represent an important step towards the construction of regional figures for the tourism sector. These results are destined to be improved in accuracy in the near future, mainly due to two advancements in the measurement of the tourism demand. As already mentioned, the excursionists' expenditure data used in this study do not include business visits and a new GB day visits survey is currently under preparation which, it is hoped, will address this issue. IPS data for inbound tourism expenditure does not include the money spent on travel tickets paid to UK companies (mainly airlines). The TIU are currently exploring the use of UK Civil Aviation Authority data to correct the IPS headline figures for inbound tourism expenditure as reported in the E-UKTSA. This would, in turn, increase the regional figures.

Further improvements could be induced
Source: Authors' calculations

Source: Authors' calculations

All these issues are out of the scope of this paper, but will benefit from these results, which can be used as an important starting point.

\section{Notes}

1 The Tourism Intelligence Unit was established in ONS in August 2008. The commitment to work on the production of regional figures for the tourism sector has been triggered by the Regional Development Agencies (RDAs) through their funding of the English Tourism Intelligence Partnership, which was instrumental in the setting up of the TIU.

2 United Nations World Tourism Organisation, Statistical Office of the European Communities, Organisation for Economic Co-operation and Development (2008), Tourism Satellite Account: Recommended Methodological Framework (TSA:RMF 2008), New York, Luxembourg, Paris, Madrid

3 The E-UKTSA has reference date 2006. ONS/TIU has already started considering improvements to the current experimental version to move towards a true publication for a UKTSA 2007. This will automatically imply an update of the regional figures.

4 The VAT threshold changes periodically. The one considered in this article refers to the period 1 April 2006 to 31 March 2007.

5 According to ONS' internal sources the IDBR covers 99 per cent of the economic activity of the UK. Furthermore, part of the information missed due to the VAT threshold is regained through the Pay As You Earn (PAYE) scheme, which is also used to construct the IDBR.

6 It is worthwhile stressing that while at the regional level we are able to have a headline reconciliation of demand and supply (as is done at the national level with the TSA), we cannot consider the result of the present methodology to be the production of regional TSAs. The most important reason for this is the lack of a consistent set of supply and use tables produced on a regional basis.

7 This figure could appear relatively low, but it is worthwhile mentioning that it more than doubles the agriculture contribution. The figure has been derived through the construction of a UK TSA, which is now moving towards publication.

\section{CONTACT} the potential environmental impacts of the tourism sector? And, does tourism promote the acquisition of new technologies locally? 